- n Noviembre pasado, los espectadores del - documental de la "Noche temática" de la 2, L que versaba sobre la "Doble vida", pudimos escuchar atónitos cómo lo que siempre considerábamos el insidioso aparato policial de la Alemania socialista, la tristemente famosa "Staatssicherheitspolizei" o "Stasi", se convirtió, por obra del diablo y de la " $\mathrm{e}$ " protésica del castellano, en una sofisticada y popular droga de diseño, el "éxtasis". La confusión fue completa. Aquí algunas citas:

"Los papeles de lbrahim Böhme fueron creados por la éstasi" ¿Será que los ha escrito bajo el efecto euforizante de la sustancia prohibida? Asi le ha ido.

"Los víctimas de la éstasi pudieron ver sus expedientes." Claro, en el nuevo estado de derecho, también los estasimanos pueden recurrir. "...habla de su primer contacto con la éstasi..." ¿A que fue con los amiguetes en una discoteca de bakalao?

$Y$, finalmente, la éstasi, más que una droga, parece toda una ideología, una especie de secta. "...he trabajado para ella, no en ella..."

Si de verdad fuera asi, o sea, que la Stasi era el éstasi, ya no extraña tanto que colaborara tanta gente. Primero les dieron de probar, y luego, hala, a espiar a todo el mundo para conseguir su dosis diaria.

Estamos rodeados por transmisores de todo tipo. La vida de hoy en dia más que nunca está llena de mensajes codificados, de secretos y misterios.

\title{
¿"STASI" O "STASI"? ¿LA ANTIGUA POLICÍA SECRETA DE LA RDA EN REALIDAD FUE UNA DROGA?
}

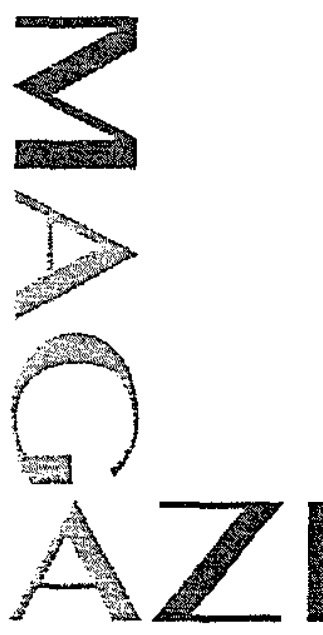

\author{
Christoph Ehlers - E.O.I. San Ropue
}

